\title{
SURVEI TINGKAT KETERAMPILAN DASAR SHOOTING PADA SISWA EKSTRAKURIKULER SEPAKBOLA DI SMAN 1 SURADE
}

\author{
Jamudin ${ }^{1}$, Ruslan Abdul Gani ${ }^{2}$, Saepul Ma'mun ${ }^{3}$ \\ Universitas Singaperbangsa Karawang ${ }^{1,2,3}$ \\ E-mail : jamudinjam@gmail.com
}

\begin{abstract}
ABSTRAK
Penelitian ini di latar belakangi dengan permasalahan penyelesaian akhir dari pemain SMAN 1 Surade yang seringkali tidak menemui sasaran atau cenderung pelan dilihat dari beberapa pertandingan lembaga ini sering mendapatakan statistic peluang yang cukup banyak akan tetapi sangat minim yang menjadi gol.Tujuan penelitian ini adalah untuk mengetahui seberapa besar tingkat keteramilan dasar shooting / Menendang dalam permainan Sepakbola pada siswa peserta ekstrakurikuler di SMAN 1 Surade Kabupaten Sukabum. Subjek dalam penelitian ini adalah seluruh siswa yang mengikuti kegiatan ekstrakurikuler sepakbola putra di SMAN 1 Surade yang berjumlah 31 orang. Teknik pengumpulan data yang digunakan dalam penelitian ini adalah deskriptif kuatitatif. Metode yang digunakan adalah survey dengan tekhnik tes adapun pengumpulan data menggunakan intrumen tes, Intrumen yang digunakan terdiri dari dua isntrumen 1) Instrumen keterampiln Shooting/Menendang 2) istrumen hasil Shooting / menendang bola yang bertujuan untuk mengetahui kualitas Shooting / menendang Bola yang di miliki oleh para peserta ekstrakurikuler di SMAN 1 Surade Kabupaten Sukabumi. Hasil dari peneliatan menggunakan instrumen keterampilan menyatakan 1 orang siswa pada kategori "Sangat Baik" dengan persentase 3,2\%, 3 orang siswa pada kategori "Baik" dengan persentase 9,7\%,8 orang pada kategori "Sedang" dengan persentase 25,8\%, 12 orang pada kategori "Kurang" dengan persentase 38,7\%, dan 7 orang siswa pada kategori "Sangat Kurang". Dengan persentase $22,6 \%$.
\end{abstract}

Kata Kunci: Tingkat Keterampilan Shooting Sepakbola

\begin{abstract}
The purpose of this study was to determine how big the level of basic shooting / kicking skills in soccer games for students participating in extracurricular activities at SMAN 1 Surade, Sukabumi Regency, the subjects in this study were all students who took part in men's soccer extracurricular activities at SMAN 1 Surade totaling 31 people, The data collection technique used in this research is quantitative descriptive. The method used is a survey with a test technique as for data collection using test instruments, the instruments used consist of two instruments 1) Shooting / Kicking skill instruments 2) Shooting / kicking ball results instruments. which aims to determine the quality of shooting / kicking the ball that is owned by the extracurricular participants at SMAN 1 Surade Sukabumi Regency, the results of the study using a skill instrument stated that 1 student was in the "Very Good" category with a percentage of 3.2\%, 3 students in the "Good" category with a percentage of 9.7\%, 8 students in the "Medium" category with a percentage of 25.8\%, 12 students in the "Poor" category with a percentage of 38.7\%, and 7 students in the "Very Poor" category. "With a percentage of $22.6 \%$.
\end{abstract}

Key Words: Football Shooting Skills Level

Dipublikasikan Oleh :

UPT Publikasi dan Pengelolaan Jurnal

Universitas Islam Kalimantan Muhammad Arsyad Al-Banjari Banjarmasin 


\section{PENDAHULUAN}

Olahraga adalah kegiatan pelatihan fisik, yaitu kegiatan fisik untuk memperkaya dan meningkatkan kemampuan kapasitas dan keterampilan dasar serta gerakan keterampilan (kecabangan olahraga). Kegiatan ini merupakan bentuk pendekatan aspek kesehatan fisik, yang berarti juga sehat dinamis yaitu sehat yang disertai dengan kemampuan gerak yang memenuhi segala tuntutan gerak kehidupan sehari-hari. Ini berarti bahwa semua orang yang melakukan pendidikan jasmani melalui kegiatan olahraga memiliki tingkat kondisi fisik yang memadai, itu hanya satu tujuan, yaitu pemeliharaan atau peningkatan tingkat aktivitas kesehatan dan gerakan.(Bangun, 2016). Maka dari itu olahraga merupakan salah satu cara untuk menjaga kebugaran jasmani dan rohani agar kondisi tetap terjaga dengan baik dan stabil. Banyak terlihat di kalangan pria maupun wanita, orang tua ataupun anak muda melakukan gerakan-gerakan latihan olahraga, baik itu di lapangan maupun di sekitaran rumah dengan lahan yang luas, semua itu di lakukan oleh mereka agar kesehatan dan kesegaran jasmani tetap baik ,semua itu digunakan sebagai dasar penting untuk hidup bahagia dan bermanfaat.Melakukan aktvitas Berolahraga dapat meningkatkan kebugaran jasmani atau kondisi fisik seseorang sehingga mampu melaksanakan aktivitas sehari-hari tanpa mengalami kelelahan yang berlebihan.

Pendidikan jasmani olahraga dan kesehatan merupakan satu mata ajar yang diberikan disuatu jenjang sekolah tertentu yang merupakan salah satu bagian dari pendidikan keseluruhan yang mengutamakan aktivitas jasmani dan pembinaan hidup sehat untuk bertumbuh dan berkembang, jasmani, mental, sosial dan emosional yang serasi, selaras dan seimbang(Putri et al., 2021). Pendidikan jasmani merupakan bagian integral dari system pendidikan secarara menyeluruh, yang bertujuan untuk meningkatkan dan mengembangkan aspek kesehatan, kebugaran jasmani, keterampilan berfikir kritis, stabiltas emosiaonal,keterampilan sosial, penalaran dan tindakan moral melalui aktivitas jasmani dan olah penyelenggaraan pendidikan sebagai suatu tahapan pembinaan manusiayang berlangsung selama manusia itu hidup, peran pendidikan jasmani sangat penting yang dapat memberikan kesempatan pada siswa untuk langsung terlibat dalam aneka pengalaman belajar melalui aktivitas jasmani, permaianan dan olahraga yang dilakukan secara bertahap. Pembekalan pengalaman pembelajaran itu diarahkan untuk membina, sekaligus membentuk gaya hidup sehat dan aktif semasa hidup. Keberhasilan dalam pembelajaran pendidikan jasmani itu juga tergantung pada proses interaksi yangdiawali dengan persepsi pelaku pendidikan, yaitu siswa dan guru terhadap proses belajar mengajar pendidikan jasmani(Prasetyo et al., 2021)

Dalam suatu lembaga sekolah ada suatu kegiatan ekstrakurikuler. Kegiatan ekstrakurikuler merupakan suatu kegiatan yang ada di luar jam proses pembelajaran yang diperuntukan untuk mewadahi dan mempasilitasi siswa yang ingin mengembangkan kemampuan yang dimilikinya di bidang non akademik, kegiatan ektrakurikller ini bertujuan untuk mengembangkan potensi-potensi yang dimiliki siswa di bidang non akademik yang ada di sekolah seperti mengembangkan keterampilan-keterampilan dalam bidang olahraga. Surat Keputusan Mendikbud Nomor 060/U/1993 dan Nomor 080/U/1993(Asep Herry H, dkk, 2006: 12.4), dijelaskan bahwa, kegiatan ekstrakurikuler merupakan suatu kegiatan yang diselenggarakan diluar jam pelajaran yang dicantum dalam susunan program sesuai dengan keadaan dan kebutuhan sekolah. Kegiatan ekstrakurikuler bisa berbentuk sebuah kegiatan pengayaan dan kegiatan perbaikan yang berhubungan dengan program kurikuler.(Sakee, 2014). Kegiatan ekstrakurikuler di suatu lembaga sekolah biasanya terbagi menjadi beberapa bidang salah satunya bidang cabang olahraga Sepakbola, Sepakbola merupakan satu dari beberapa cabang olahraga yang sangat populer di Indonesia bahkan di seluruh dunia. Hampir semua kaum laki-laki dari anak-anak, remaja pemuda orang tua pernah melakukan olahraga sepakbola meskipun tujuan mereka melakukan aktivitas olahraga ini berbeda-beda ada yang sekedar untuk rekreasi atau kesenangan diri, untuk menjaga kebugaran atau sekedar menyalurkan hobi/kesenangan. Ada juga yang bertujuan untuk mencapai sebuah prestasi diri sebagai pemain sepakbola profesional. banyaknya kompetisi liga super, divisi utama divisi satu dan sebagainya menunjukkan bahwa masyarakat masih memiliki antuasiasme tinggi terhadap perkembangan sepakbola di tanah air(Susanto \& Lismadiana, 2016)

Berdasarkan observasi dan wawancara yang saya lakukan kepada coach Hendra Sutiawan selaku pelatih ektrakurikuler sepakbola di SMAN 1 Surade beliau menjelaskan bahwa lembaga ini merupakan salah satu sekolah yang diperhitungkan khususnya didalam bidang non akademik cabang olahraga sepakbola yng mana beliau menjelaskan diantara prestasi tersebut ada yang di raih di dalam kota dan ada juga yang di raih di luar kota,

Dipublikasikan Oleh :

UPT Publikasi dan Pengelolaan Jurnal

Universitas Islam Kalimantan Muhammad Arsyad Al-Banjari Banjarmasin 
pada kejuaraan antar SMA/SMK sederajat pada sektor putra, Akan tetapi dibalik itu semua masih banyak pekerjaan rumah yang harus kami perbaiki salah satunya adalah penyelesaian akhir dari pemain pemain SMAN 1 Surade seringkali tidak menemui sasaran atau cenderung pelan dilihat dari beberapa pertandingan lembaga ini sering mendapatakan statistic peluang yang cukup banyak akan tetapi sangat minim yang menjdi gol. Oleh karena itu saya ingin mengetahui bagaimana tingkat kemampuan keterampilan dasar shooting yang di miliki oleh anak anak peserta ekstrakurikuler sepakbola SMAN 1 Surade dengan menggunakan instrumen dengan maksud ingin mengetahui tingkat keterampilan dasar shooting pada peserta ekrtakurikuler sepakbola SMAN 1 Surade.

\section{METODE}

Penelitian ini menggunakan pendekatan kuantitatif dengan menggambarkan atau menganalisis hasil penelitian dan metode yang digunakan yaitu survey. Untuk pengumpulan data melalui penggunaan instrumen tes. (Sugiyono (2010:92).)menjelaskan bahwa Instumen penelitian digunakan untuk mengukur nilai variabel yang diteliti. Karena instrumen penelitian akan digunakan untuk melakukan pengukuran dengan tujuan menghasilkan data kuantitatif yang akurat, maka setiap instrumen harus mempunyai skala. Instrumen yang penulis gunakan dalam penelitian ini adalah tes yang di adopsi dari pebelitian terdahulu yang dilakukan oleh Heri Islahudin dengan judul "Tingkat Keterampilan Bermain Sepakbola Si swa Peserta Ekstrakurikuler Sepakbola di SMA Negeri Rembang Kab. Purbalingga".Instrumen diperlukan agar pekerjaan yang dilakukan lebih mudah dan hasilnya lebih baik, dalam arti lebih cermat, lengkap, dan sistematis sehingga lebih mudah diolah.Instrumen yang digunakan peneliti berupa tes dengan tes ini dilakukan untuk memperoleh hasil yang benar sesuai denga kondisi keterampilan shooting yang dimiliki oleh siswa ekstrakurikuler sepakbola di SMAN 1 Surade. Pengambilan data dilakukan oleh 2 testor yaitu satu orang pelatih ekstrakurikuler SMA sebagai penulis dan mahasiswa peneliti sebagai timer dan memberi tata cara pelaksanaan untuk menghindari kesalahan pengukuran.

Menurut (Islahudin, 2012) menjelaskan bahwa dalam suatu penelitian seorang peneliti dapat menggunakan dua jenis analsis yaitu analisis statistik dan non statistic". Analisis ini dilakukan untuk mengetahui tingkat ketrampilan dasar Shootng dalam permainan sepakbola pada anggota ekstrakurikuler sepakbola di SMAN 1 Surade. Teknik analisis data yang di gunakan dalam penelitian ini adalah statistic deskriptif. Statistic ini dilakukan untuk mengumpulkan data, menyajikan data, dan menentukan nilai. Selanjutnya dipakai pada pembahasan permasalahan dengan mengacu pada standar kemampuan dasar bermain sepakbola yang sudah di tentukan.

Data-data yang diperoleh tiap-tiap item tes merupakan data kasar dari hasil tiap butir yang dicapai siswa. Selanjutnya hasil tersebut diubah menjadi nilai dengan mengkonsultasikan data dari tiap-tiap item tes yang telah dicapai siswa dengan kategori yang sudah ditentukan, pengkategorian dikelompokkan menjadi 5 kategori. Kriteria penilaiannya adalah sebagai berikut:

\begin{tabular}{|l|l|}
\hline Baik Sekali & $: \mathrm{M}+1,5 \mathrm{SD} \leq \mathrm{X}$ \\
\hline Baik & $: \mathrm{M}+0,5 \mathrm{SD} \leq \mathrm{X}<\mathrm{M}+1,5 \mathrm{SD}$ \\
\hline Cukup & $: \mathrm{M}-0,5 \mathrm{SD} \leq \mathrm{X}<\mathrm{M}+0,5 \mathrm{SD}$ \\
\hline Kurang & $: \mathrm{M}-1,5 \mathrm{SD} \leq \mathrm{X}<\mathrm{M}-0,5 \mathrm{SD}$ \\
\hline Kurang Sekali & $: \mathrm{X}<\mathrm{M}-1,5 \mathrm{SD}$ \\
\hline
\end{tabular}

Tabel 1. Sumber : (Anas Sudijono 2009:453)

Setelah data dikelompokkan dalam kategori, kemudian mencari persentase masing-masing data dengan rumus persentase. Menurut Suharsimi Arikunto rumus persentase yang digunakan adalah:

Keterangan:

$\mathrm{P}$ : persentase yang dicari

$P=-\mathrm{x} 100 \%$

Dipublikasikan Oleh :

UPT Publikasi dan Pengelolaan Jurnal

Universitas Islam Kalimantan Muhammad Arsyad Al-Banjari Banjarmasin 


\section{$F$ \\ $N$}

Sumber : Suharsimi Arikunto, (2011:

$$
\mathrm{N} \text { : jumlah responden }
$$

\section{HASIL DAN PEMBAHASAN}

Untuk mengetahui nilai proses tingkat keterampilan dasar shooting dalam permaianan sepakbola pada siswa yang mengikuti kegiatan ekstrakurikuler sepakbola di SMAN 1 Surade Kabupaten Sukabumi diukur dengan kisi kisi intrumen tes keterampilan teknik dasar shooting, Setelah data diperoleh di skor dan di analisis dengan menggunakan bantuan software Microsoft Excel 2010, diperoleh data nilai minimum =3, Nilai maksimum =12, Nilai rata - rata (mean) 6.10 ; Standar deviasi 1.97.

Tabel 2.

Nilai Proses Keterampilan Shooting Siswa Ektrakurikuler Sepakbola di SMAN 1 Surade Kelas interval Frekuensi Presentase Kriteria

\begin{tabular}{cccccc}
\hline $\mathbf{8 5}$ & - & 100 & 1 & 3.2 & Sangat Baik \\
$\mathbf{7 2}$ & - & 84 & 3 & 9.7 & Baik \\
$\mathbf{5 6}$ & - & 71 & 8 & 25.8 & Sedang \\
$\mathbf{4 0}$ & - & 55 & 12 & 38.7 & Kurang \\
$\mathbf{2 5}$ & - & 39 & 7 & 22.6 & Sangat Kurang \\
& & Jumlah & & 31 & 100 \\
\hline
\end{tabular}

Dari hasil penelitian tersebut diketahui bahwa tingkat keterampilan dasar shooting / menendang pada siswa yang mengikuti ekstrakurikuer sepakbola di SMAN $1 \mathrm{~S}$ urade yang menyatakan pada kategori "sangat baik" dengan persentase 3,2 \%, Pada kategori baik dengan persentase 9.7\%, Pada kategori sedang dengan persentase $25.8 \%$, Pada kategori kurang dengan persentase $38,7 \%$, Pada kategori sangat kurang dengan persentase $22,6 \%$.

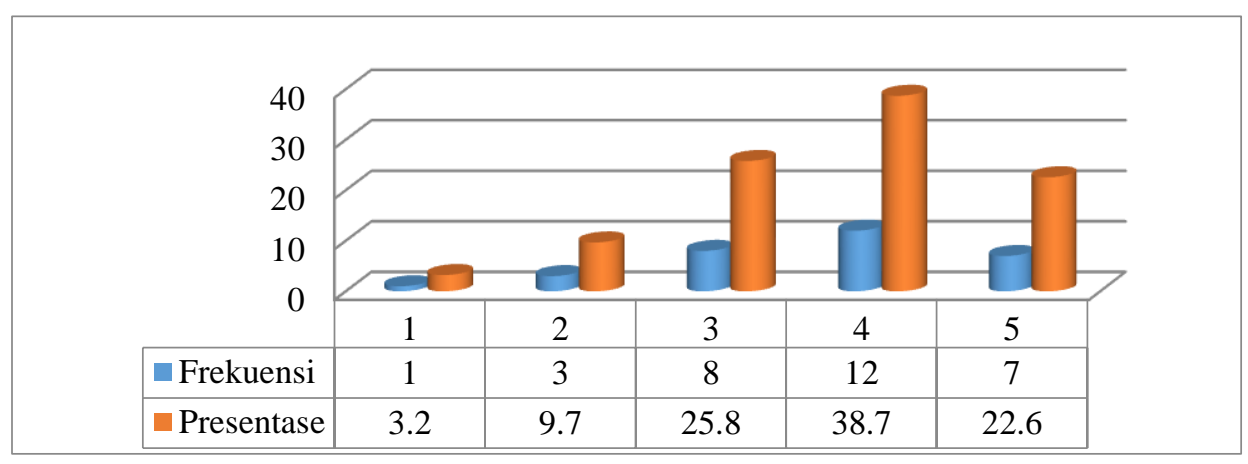

Gambar 1. Nilai Proses Keterampilan Shooting Siswa Ektrakurikuler Sepakbola di SMAN 1 Surade

Selanjutnya untuk mengetahui hasil shooting / menendang yang dilakukan oleh siswa yang mengikuti ekstrakurikuler sepakbola di SMAN 1 Surade di ukur dengan menggunakan kisi kisi intrumen tes kemampuan gerak shooting / menendang kemudian langkah selanjutnya setelah data di peroleh di skor dan di analisis dengan menggunakan bantuan software Microsoft excel 2010. Diperoleh nilai minimum $=6$ Nilai maksimum $=61$ Nilai rata - rata (mean) 30, Standar deviasi 40.0

Tabel 3.

Dipublikasikan Oleh : 
Nilai Hasil Keterampilan Shooting Siswa Ekstrakurikuler Sepakbola SMAN 1 Surade

\begin{tabular}{|c|c|c|c|c|c|}
\hline \multicolumn{3}{|c|}{ Kelas Interval } & Frekuensi & Persentase \% & Kriteria \\
\hline 51 & & 61 & 3 & 10 & Sangat Baik \\
\hline 40 & - & 50 & 5 & 16 & Baik \\
\hline 29 & - & 39 & 9 & 29 & Sedang \\
\hline 17 & - & 28 & 11 & 35 & Kurang \\
\hline 6 & . & 16 & 3 & 10 & Sangat Kurang \\
\hline \multicolumn{3}{|c|}{ Jumlah } & 31 & 100 & \\
\hline
\end{tabular}

Dari hasil penelitian tersebut diketahui bahwa tingkat keterampilan dasar shooting / menendang pada siwa yang menikuti kegiatan ekstrakurikuler sepakbola di SMAN 1 Surade yang di nyatakan 3 orang siswa pada kategori "sangat baik" dengan persentase 10\%, 5orang siswa pada kaegori "baik" dengan persentase $16 \%$, 9 orang siswa pada kategori "sedangan" dengan persentase $29 \%, 11$ orang siswa pada kategori "kurang" dengan persentase $35 \%$ ,dan pada ketegori "sangat kurang" terdapat 3 siswa dengan persentase $10 \%$.

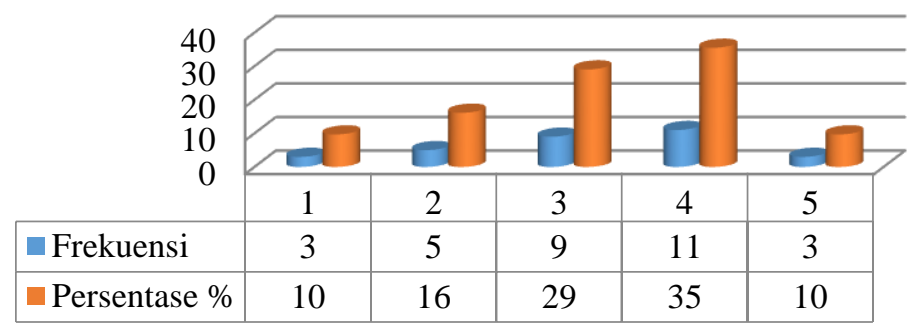

Gambar 2. Nilai Hasil Keterampilan Shooting Siswa Ekstrakurikuler Sepakbola SMAN 1 Surade

Setelah nilai hasil dan nilai proses di dapatkan lngkah selanjutnya adlah menghitung nilai ahir, untuk mengetahui nilai ahir tingkat keterampilan dasar shooting dalam permaianan sepakbola pada siswa yang mengikuti kegiatan ekstrakurikuler di SMAN 1 Surade Kabupaten Sukabumi diukur dengan kisi kisi intrumen tes keterampilan teknik dasar shooting, Setelah data diperoleh di skor dan di analisis dengan menggunakan bantuan software Microsoft Excel 2010, diperoleh data nilai minimum =17, Nilai maksimum =68, Nilai rata - rata (mean)40.6 ; Standar deviasi 30.1 .

Tabel 4.

Nilai Akhir Keterampilan Dasar Shooting Siswa Ekstrakuriluler Sepakbola SMAN 1 Surade

\begin{tabular}{cccccc}
\hline \multicolumn{2}{c}{ Interval } & Frekuensi & Persentase \% & Kategori \\
\hline $\mathbf{8 0}$ & - & 100 & 0 & 0 & Sangat Baik \\
$\mathbf{7 0}$ & - & 79 & 0 & 0 & Baik \\
$\mathbf{6 0}$ & - & 69 & 4 & 13 & Sedang \\
$\mathbf{5 0}$ & - & 59 & 2 & 6 & Kurang \\
& $<$ & 49 & 25 & 81 & Sangat Kurang \\
& & & & & \\
\hline
\end{tabular}

Dari hasil pengabungan antara nilai proses dan nilai hasil maka, diketahui bahwa tingkat keterampilan dasar shooting / menendang pada siwa yang menikuti kegiatan ekstrakurikuler sepakbola di SMAN 1 Surade yang di nyatakan 4 orang siswa pada kategori " sangat baik" dengan persentase 13\%, 4 orang siswa pada kaegori "baik"

Dipublikasikan Oleh :

UPT Publikasi dan Pengelolaan Jurnal

Universitas Islam Kalimantan Muhammad Arsyad Al-Banjari Banjarmasin 
dengan persentase 13\%, 12 orang siswa pada kategori "sedangan" dengan persentase 39\%, 8 orang siswa pada kategori "kurang" dengan persentase $26 \%$,dan pada ketegori "sangat kurang" terdapat 3 siswa dengan persentase $10 \%$.

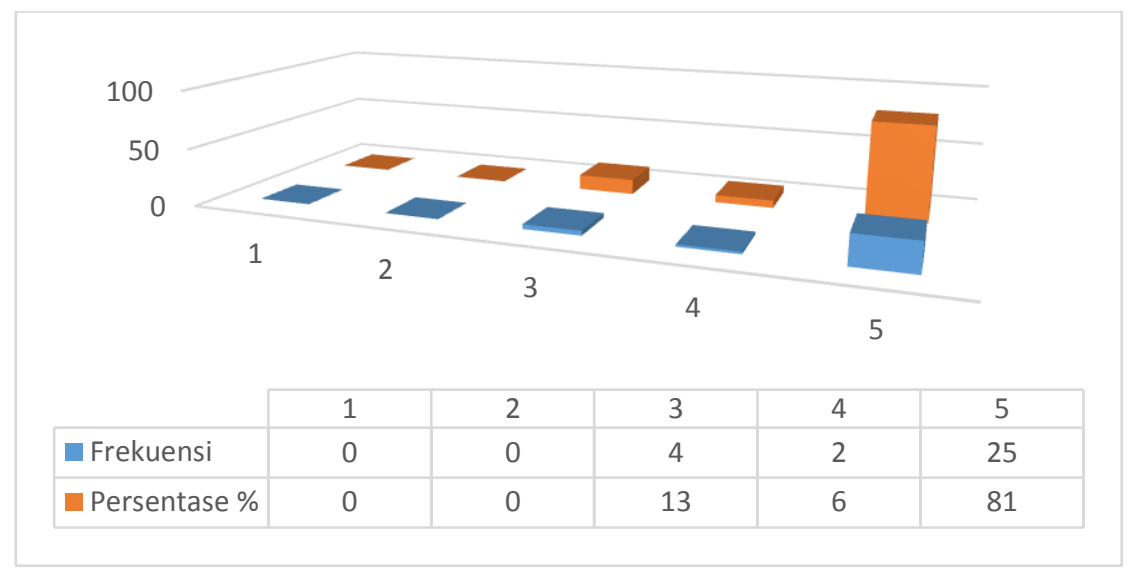

\section{Gambar 3. Nilai Akhir Keterampilan Dasar Shooting Siswa Ekstrakuriluler Sepakbola SMAN 1 Surade}

Berdasarkan penelitian yang telah di lakukan oleh peneliti diperoleh data nilai proses tingkat keterampilan dasar shooting pada siswa ekstrakuler di SMAN 1 surade, berdasrkan istrumen tes keterampilan teknik dasar shooting siswa ekstrakurikuler sepakbola di SMAN 1 Surade, menyatakan bahwa 1 orang siswa dalam kategori "sangat baik" dengan persentase 3.2\%, Pada kategori "baik" sebanyak 3 orang siswa dengan persentase 9.7\%, Pada kategori "sedang" sebanyak 8 orang siswa dengan persentase 25.8, pada kategori "kurang" sebanyak 12 orang siswa dengan persentase 38\%, kemudian pada kategori "sangat kurang" sebanyak 7 orang siswa dengan persentase 22.6 .

Kemudian berdasarkan penelitian yang telah dilakukan dengan pengambilan data menggunakan instrument tes kemampuan Shooting Siswa Ekstrakurikuler sepakbola SMAN 1 Surade diperoleh data nilai hasil sebanyak 3 orang siswa pada kategori " sangat baik" dengan persentase 10\%, 5orang siswa pada kaegori "baik" dengan persentase 16\%, 9 orang siswa pada kategori "sedangan" dengan persentase 29\%, 11 orang siswa pada kategori "kurang" dengan persentase 35\% , dan pada ketegori "sangat kurang" terdapat 3 siswa dengan persentase $10 \%$.

Dari hasil pengabungan antara nilai proses dan nilai hasil maka didapatkan nilai akhir, bahwa tingkat keterampilan dasar shooting / menendang pada siwa yang menikuti kegiatan ekstrakurikuler sepakbola di SMAN 1 Surade yang di nyatakan 0 siswa pada kategori " sangat baik" dengan persentase 0\%, 0 siswa pada kaegori "baik" dengan persentase $0 \%$, 4orang siswa pada kategori "sedang” dengan persentase 14\%, 2orang siswa pada kategori "kurang” dengan persentase 6\%,dan pada ketegori "sangat kurang" terdapat 25 siswa dengan persentase $81 \%$.

Berdasarkan hasil penelitian yang dilakukan, Peneliti berhasil mendapatkan data mentah dan kemudian di olah dengan menggunakan software mikrosoft excel 2010, dari hasil pengolahan data ada beberapa siswa dalam kategori sangat baik, Baik, Sedang, Kurang, dan Sangat kurang. Setelah saya wawancarai Coach Hendra Sutiawan atau biasa di panggil Coach Pahe dari beberapa kategori tersebut siswa yang mendapatkan nilai "Sangat baik" merupakan siswa yang memiliki keterampilan gerak baik, sering mengikuti latihan dan cepat tanggap dalam memahami materi yang di berikan pelatih, kemudia siswa yang termasuk kedalam kategori "Baik" adalah siswa yang sering mengikuti latihan, memiliki keterampilan dasar yang baik akan tetapi agak lemot dalam menanggapi dan melakukan apa yang di perintahkan pelatih, pada kategori sedang ini merupakan kategori terbanyak penyebabnya adalah siswa ini tidak memiliki keterampilan gerak dasar yang baik sehingga mereka harus memulai belajar dari nol, meskipun mereka sering ikut berlatih, pada kategori " kurang" mereka adalah peserta ektrakurikuler yang jarang mengikuti latihan, yang terakhir adalah kategori "Sangat kurang" merka adalah siswa yang memiliki kemampuan tekhik dasar buruk jarang mengikuti latihan, dan pemalas.

Dipublikasikan Oleh :

UPT Publikasi dan Pengelolaan Jurnal

Universitas Islam Kalimantan Muhammad Arsyad Al-Banjari Banjarmasin 
Dari hasil penghitungan keseluruhan penelitian ini dapat di simpulkan bahwa kemampuan teknik dasar shooting yang di miliki siswa peserta Ekstra kurikuler yang ada di SMAN 1 Surade rata rata berada dalam kategori sangat kurang.

\section{PENUTUP}

Berdasarkan penelitian yang telah di lakukan oleh peneliti diperoleh data nilai proses tingkat keterampilan dasar shooting pada siswa ekstrakuler di SMAN 1 surade, berdasrkan istrumen tes keterampilan teknik dasar shooting siswa ekstrakurikuler sepakbola di SMAN 1 Surade, menyatakan bahwa 1 orang siswa dalam kategori "sangat baik" dengan persentase 3.2\%, Pada kategori "baik" sebanyak 3 orang siswa dengan persentase 9.7\%, Pada kategori "sedang" sebanyak 8 orang siswa dengan persentase 25.8, pada kategori "kurang" sebanyak 12 orang siswa dengan persentase 38\%, kemudian pada kategori "sangat kurang" sebanyak 7 orang siswa dengan persentase 22.6 .

Kemudian berdasarkan penelitian yang telah dilakukan dengan pengambilan data menggunakan instrument tes kemampuan Shooting Siswa Ekstrakurikuler sepakbola SMAN 1 Surade diperoleh data nilai hasil sebanyak 3 orang siswa pada kategori " sangat baik" dengan persentase 10\%, 5orang siswa pada kaegori "baik" dengan persentase 16\%, 9 orang siswa pada kategori "sedangan" dengan persentase 29\%, 11 orang siswa pada kategori "kurang" dengan persentase $35 \%$, dan pada ketegori "sangat kurang" terdapat 3 siswa dengan persentase $10 \%$.

Dari hasil pengabungan antara nilai proses dan nilai hasil maka didapatkan nilai akhir, bahwa tingkat keterampilan dasar shooting / menendang pada siwa yang menikuti kegiatan ekstrakurikuler sepakbola di SMAN 1 Surade yang di nyatakan 0 siswa pada kategori " sangat baik" dengan persentase 0\%, 0 siswa pada kaegori "baik" dengan persentase 0\%, 4orang siswa pada kategori "sedang” dengan persentase 14\%, 2orang siswa pada kategori "kurang" dengan persentase 6\%, dan pada ketegori "sangat kurang" terdapat 25 siswa dengan persentase $81 \%$.

Dari hasil keseluruhan penelitian ini dapat di simpulkan bahwa kemampuan teknik dasar shooting yang di miliki siswa peserta Ekstra kurikuler yang ada di SMAN 1 Surade rata rata kurang. Saran kepada beberapa pihak seperti peneliti selanjutnya, Siswa maupun Guru berikut yaitu peneliti selanjutnya dengan adanya penelitian ini diharakan agar bisa mempermudah dan menjadi referensi untuk melakukan penelitian tentang keterampilan dasar Shooting dalam permainan Sepakbola, bagi siswa diharapkan agar lebih giat dan lebih semangat lagi dalam mengikuti proses latihan agar mendapatakan hasil yang oftimal dan mampu berprestasi sedangkan bagi Guru/pelatih dengan adanya penelitian ini diharapkan agar lebih memperhatikan keseimbangan dalam memberikan materi dan porsi latihan kususnya pada porsi latihan Shootiing . agar seluruh siswa memiliki kemampuan shooting yang baik.

\section{REFERENSI}

Anwar, S. (2013). Survei Teknik Dasar Dan Kondisi Fisik Pada Siswa Sekolah Sepak Bola (Ssb) Se Kabupaten Demak Tahun 2012. Active - Journal of Physical Education, Sport, Health and Recreation, 2(9), 596-604. https://doi.org/10.15294/active.v2i9.1861

Bangun, S. Y. (2016). Peran Pendidikan Jasmani Dan Olahraga Pada Lembaga Pendidikandi Indonesia. Publikasi Pendidikan, 6(3). https://doi.org/10.26858/publikan.v6i3.2270

Elmanisar, V. (2017). Hubungan Kelincahan dengan Kecepatan Dribbling dalam Pengembangan Diri Cabang Sepakbola. Sport Science, 17(1), 36-47. https://doi.org/10.24036/jss.v17i1.6

Fauzi, A. (2018). Ahmad Fauzi. Promedia, 4(2), 56-76.

Firdaus, B. A. P. M. (2016). Survei Keterampilan Shooting Atlet Sepakbola Di Pplpd Kabupaten Bogor. Jurnal Kejaora, 1(2), 1-7.

Gultom, Z. A. S. (2017). Survei Tingkat Pemahaman Pemain Sepak Bola Tentang Peraturan Permainan Sepak Bola (Laws of the Game) 2014/2015 Pada Klub Persatuan Sepakbola Medan Sekitarnya (Psms) Medan Tahun

Dipublikasikan Oleh :

UPT Publikasi dan Pengelolaan Jurnal

Universitas Islam Kalimantan Muhammad Arsyad Al-Banjari Banjarmasin 
2016. Survei Tingkat Pemahaman Pemain Sepak Bola Tentang Peraturan Permainan Sepak Bola (Laws of the Game) 2014/2015 Pada Klub Persatuan Sepakbola Medan Sekitarnya (Psms) Medan Tahun 2016, 1(1), 1-11.

Halim, S., \& Indriarsa, N. (2013). Minat Siswa Sma Dr. Soetomo Surabaya Pada Kegiatan Ekstrakurikuler Futsal. Jurnal Pendidikan Olahraga Dan Kesehatan, 01(01), 260-264.

Hamsa, M., \& Hartoto, S. (2015). Survey Minat Siswa Kelas VII dan VIII di SMPN 1 Bangil dalam Mengikuti Ekstrakurikuler Renang. Jurnal Pendidikan Olahraga Dan Kesehatan, 03(03), 783-788.

Hasanah, S. U. (2019). Kegiatan Ekstrakurikuler Paskibra Dalam Rangka Pembinaan Karakter Semangat Kebangsaan Siswa. Jurnal Pendidikan Kewarganegaraan, 3(2), 211. https://doi.org/10.31571/pkn.v3i2.1443

Hendri, G. (2020). Motivasi Siswa Dalam Proses Pembelajaran Pendidikan Jasmani Olahraga Kesehatan Di SMAN 1 Padang Sago Padang Pariaman. Jurnal Patriot, 2, 171-181. http://patriot.ppj.unp.ac.id/index.php/patriot/article/view/533

Hidayat Taufiq \& Kurniawan Deddy. (2015). Pengaruh Modifikasi Permainan Bolavoli Terhadap Kerjasama Siswa Pada Pembelajaran Pendidikan Jasmani, Olahraga Dan Kesehatan (Studi Pada Siswa Kelas X Boga 1 SMKN 3 Probolinggo). Jurnal Pendidikan Olahraga Dan Kesehatan, 03(1), 20-24.

Irawan, B. (2019). Manajemen Ekstrakurikuler Olahraga Sepakbola Di Sekolah Menengah Atas (Sma) SeKabupaten Brebes. https://lib.unnes.ac.id/37136/

Islahudin, H. (2012). Tingkat keterampilan Bermain sepakbola siswa peserta ekstrakurikuler sepakbola di SMA Negeri 1 Rembang Kab. Purbalinngga. Skripsi.

Jayul, A., \& Irwanto, E. (2020). Model Pembelajaran Daring Sebagai Alternatif Proses Kegiatan Belajar Pendidikan Jasmani di Tengah Pandemi Covid-19. Jurnal Pendidikan Kesehatan Rekreasi, 6(2), 190-199.

Junaedi, A., \& Winata, H. (2015). Survei Tingkat Kemajuan Pendidikan Jasmani, Olahraga, Dan Kesehatan Di Sma, Smk, Dan Ma Negeri Se-Kabupaten Gresik. Jurnal Pendidikan Olahraga Dan Kesehatan, 3(3), 834-842.

Kanca, I. N. (2018). Menjadi Guru Pendidikan Jasmani Olahraga Dan Kesehatan Di Abad 21. Prosiding Seminar Nasional IPTEK Olahraga, 21-27.

Kumala, N. E., Irianto, A., \& Yustitia, V. (2019). Ekstrakurikuler Tari untuk Penguatan Cinta Tanah Air. Jurnal Pendidikan Dasar, 3, 44-53.

Prasetyo, D. G., Gani, R. A., \& Ismaya, B. (2021). Minat Siswa Terhadap Pembelajaran Renang di SMA Negeri 5 Karawang. 2(2), 81-89.

Pratiwi, S. I. (2020). Pengaruh Ekstrakurikuler Pramuka terhadap Karakter Disiplin Siswa Sekolah Dasar. Edukatif: Jurnal Ilmu Pendidikan, 2(1), 62-70. https://doi.org/10.31004/edukatif.v2i1.90

Putri, T. eka, Kurniawan, F., \& Wijaya, H. H. (2021). Pengaruh Alat Bantu Media Terhadap Keterampilan Hasil Lay Up Shoot Pada Ekstrakurikuler Bola Basket SMA Negeri 1 Sukatani. 2(April), 142-150.

Ramadhona, H. (2016). Pemanfaatan E-Learning Berbasis Moodle Pada Pembelajaran Sepakbola. 402-407. http://pasca.um.ac.id/conferences/index.php/SNPJ/article/view/1018\%0Ahttp://pasca.um.ac.id/conferences/ind ex.php/SNPJ/article/download/1018/689\%0Ahttps://lens.org/097-205-824-829-910

Retama, M. A., Dinata, M., \& Jubaedi, A. (2018). Pengaruh Latihan Dribble 20 Yards Square Terhadap Kemampuan Menggiring Bola. Jorpres (Jurnal Olahraga Prestasi), 14(2), 149-163. https://doi.org/10.21831/jorpres.v14i2.23825

Sakee, U. (2014). Hubungan Partisipasi Mengiuti Kegiatan Ekstrakurikulerdan Kedisilinan BELAJAR Dengan

Dipublikasikan Oleh :

UPT Publikasi dan Pengelolaan Jurnal

Universitas Islam Kalimantan Muhammad Arsyad Al-Banjari Banjarmasin 
Kemandirian Blajar Siswa Sekolah Menengah Atas Neger 1 Byolali Tahun Ajaran 2013/2014. Tetrahedron Letters, 55(3), 3909.

Santoso, N. (2014). Tingkat Keterampilan Passing-Stoping Dalam Permainan Sepakbola Pada Mahasiswa Pjkr B Angkatan 2013. Jurnal Pendidikan Jasmani Indonesia, Volume 10,(November), 40-48.

Setiyawan, Kresnapati, P., \& Setiawan, D. A. (2020). Edu Sportivo (Vol. 1, Issue 1).

Sulistio, D., Sugianto, \& Defliyanto. (2019). Analisis Kemampuan Teknik Dasar Passing, Dribbling, Dan Shooting Pada Pemain Sepak Bola Ssb Putra U 10-12 Tahun Di Kabupaten Kaur. Kinestetik, 3(2), 241-248. https://doi.org/10.33369/jk.v3i2.8997

Susanto, N., \& Lismadiana, L. (2016). Manajemen program latihan sekolah sepakbola (SSB) GAMA Yogyakarta. Jurnal Keolahragaan, 4(1), 98-110. https://doi.org/10.21831/jk.v4i1.8133

Taufiqurriza, H. (2012). Tingkat Keterampilan Dasar Permainan Sepak Bola Pada Siswa Sekolah Dasar. Active Journal of Physical Education, Sport, Health and Recreation, 1(1), 1-3. https://doi.org/10.15294/active.v1i1.266

Yulianto, P. F. (2016). Perbedaan Pengaruh Pendekatan Pembelajaran Metode Bagian dan Keseluruhan Terhadap Peningkatan Dribble Shooting Sepakbola Ditinjau Dari Koordinasi Mata-Kaki. Jurnal Ilmiah SPIRIT, 16(1), 14-29. http://ejournal.utp.ac.id/index.php/JIS/article/view/502

Dipublikasikan Oleh :

UPT Publikasi dan Pengelolaan Jurnal

Universitas Islam Kalimantan Muhammad Arsyad Al-Banjari Banjarmasin 